\title{
Strong sterling hits European researchers
}

Natasha Loder

Young scientists in Europe have a new cause for worry: the weakness of the euro. Postdocs and research students receiving European Commission (EC) fellowships, particularly in Britain, are complaining that their salaries are worth up to $30 \%$ less than they were in the mid-1990s, as the value of Europe's new single currency has steadily declined.

The extent of the problem emerged in an international survey by the Marie Curie Fellowship Association (MCFA) of 200 past and present Marie Curie researchers. These fellowships are individual research training grants for scientists wanting to do research in any part of the European Union (EU) other than their home country.

Many fellows studying in Britain which has not joined the euro - worry about the effect of its declining value on their salary. For various reasons they already receive one of the lowest salaries in Europe, even though Britain is one of the most expensive countries to live in.

The problem is not restricted to the United Kingdom. Four other EU countries are outside the euro zone, and one survey respondent from Sweden reported expecting a salary cut next year.

Ana Cerdeño, vice-chair of the MCFA and a postdoctoral researcher at the Sanger Centre in Cambridge, says the problem has affected all Marie Curie fellows in Britain, numbering several hundred at any one time. An added complication is that, although the

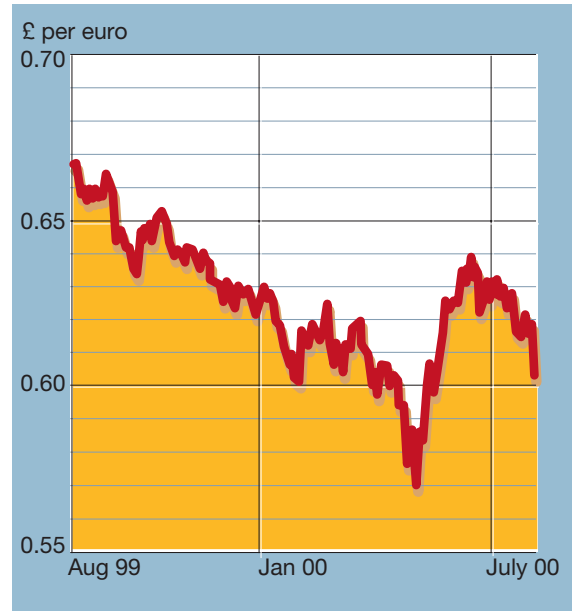

Ups and downs: the euro's troubled path.

commission pays salaries directly to host institutions, these institutions vary in how they deal with the currency-exchange issue.

When Cerdeño started a Marie Curie predoctoral fellowship at the John Innes Centre in Norwich in 1996, her grant was paid in European currency units (the euro's predecessor) and was worth $£ 1,200(\$ 1,800)$ a month. By 1999, it was worth only $£ 850$.

Cerdeño says that when the drop in the exchange rate was first noticed, the centre asked fellows to repay overpaid salary - she was asked for $£ 200$. After this, monthly revisions were made, leaving researchers uncertain about how much they were going to receive from month to month.
Karine Rizzoti, a postdoc at the Medical Research Council's National Institute of Medical Research in London, has her salary paid into her bank account in euros. As a result, its value changes from month to month - and she had to pay a surcharge to change it into pounds sterling.

Some universities, such as Manchester and Cambridge, deal with the fluctuating exchange rate by setting the monthly salary for postdocs at a low but guaranteed rate. If money is left at the end of the fellowship, they provide the remainder as a lump sum. "I think this is a fair deal as far as the university is concerned," says Sijbren Otto, a postdoc at the University of Cambridge. But he adds: "It would be much better if the EU guaranteed a salary in a local currency for fellows in countries that have not joined the euro."

Patrik Floreen, an EC scientific officer who specializes in Marie Curie fellowships, says the EC has been aware of the problem for some time, but has no control over the money once it has left Brussels. "The commission counts in euros," he says. Funds for fellowships are determined at the time the award is made, says Floreen, and no allowance is made for changes in the exchange rate.

Why not increase the salary? "Currency can fluctuate in both directions," says Floreen. "If the exchange rate were to become more favourable, we would not ask for the 'excess' money back."

http://www.mariecurie.org/

\section{Microsoft moguls back search for ET intelligence}

\section{Rex Dalton, San Diego}

Two former Microsoft executives, Paul Allen and Nathan Myhrvold, are to provide \$12.5 million to build a broadband telescope array to aid the search for extra-terrestrial intelligence (SETI).

The 'Allen Telescope Array' will be built by the SETI Institute, based in Mountain View, California, and the University of California (UC) at Berkeley. A set of small dishes distributed over a hectare, it will allow astronomers to scan nearby stars at frequencies from $\mathbf{5 0 0}$ megahertz to 10 gigahertz - an unprecedented breadth of wavelengths (see Nature 397, 552; 1999).

The 'hectare array' will be located at UC Berkeley's Hat Creek Observatory in an isolated region of northeastern California, where the university operates an array of millimetre-wavelength telescopes. Berkeley scientists will build the telescope, officials said, with SETI coordinating development of associated computer equipment.
Allen, a billionaire, was a founder of Microsoft with Bill Gates; Myhrvold was its chief technology officer before leaving the company. Allen has given $\$ 11.5$ million for the new equipment - having previously donated \$3 million to SETI - and Myhrvold \$1 million.

"For the first time, we have the ability to pursue a scientifically and technologically sophisticated search for intelligent life beyond Earth, at the same time we are doing radioastronomy," said Allen in a statement.

As well as searching for extra-terrestrial intelligence, the array will be a prototype for a kilometre-square array that may be built in Australia for larger-scale explorations. It will also test theories for suppressing exploration-hindering frequency interference, such as that from satellites.

"The Allen Telescope Array can be used by both radio astronomers and SETI

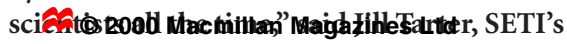
director of research. The plan came out of a

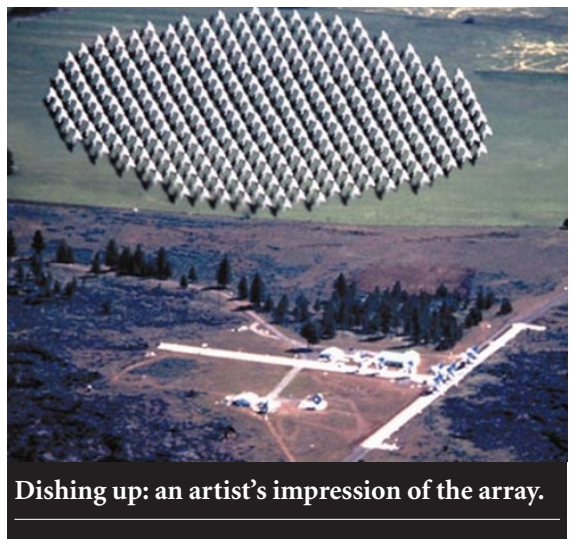

SETI workshop two years ago.

According to Jack Welch, a UC Berkeley astronomer and SETI board member, the university will operate the Allen Telescope Array using state funds for astronomy, and plans to seek future funding from the National Science Foundation.

http://www.seti-inst.edu/ 